\title{
Effect of Food Ingestion on Intestinal Glucagon-Like Immunoreactivity (GLI) Secretion in Normal and Gastrectomized Subjects***
}

\author{
J. Marco, J. A. Hedo, M. L. Villanueva, C. Calle, A. Corujedo, and J. M. Segovia \\ Clínica Puerta de Hierro, Universidad Autónoma de Madrid, Madrid, Spain
}

\begin{abstract}
Summary. This work was undertaken to compare the intestinal GLI responses to oral glucose $(1.75 \mathrm{~g} / \mathrm{kg}, 25 \%$ sol. $)$, to a carbohydrate-rich meal (carbohydrate content about $1.75 \mathrm{~g} / \mathrm{kg}$ ) and to a protein meal (250-400 g grilled lean beef) in normal $(n=6)$ and gastrectomized $(n=6)$ subjects. As expected, after glucose administration the elevation of plasma GLI was more pronounced in the gastrectomy group $(\simeq 500 \%$ above baseline) than in the controls $(\simeq 75 \%$ above baseline). However, the gastrectomized patients responded to the carbohydrate meal with a very slight elevation of circulating GLI ( $\simeq 45 \%$ above baseline), similar to that found in the controls $(\simeq 70 \%$ above baseline). After the protein meal, a small increase of GLI was also observed in both groups. - In conclusion, in gastrectomized subjects the ingestion of natural foodstuffs is followed by a normal elevation of plasma GLI, thereby suggesting the exclusion of this factor from involvement in the constellation of postgastrectomy syndrome. In these patients, the exaggerated rise in GLI after oral glucose is not representative of increments after physiological stimuli.
\end{abstract}

Key words: Gastrectomized and normal subjects, glucose and food ingestion, glucagon, intestinal glucagon-like immunoreactivity (GLI), insulin.

\footnotetext{
* Presented at the 9th Annual Meeting of the European Society for Clinical Investigation, April 24, 1975, Rotterdam, The Netherlands

** Supported in part by a research grant (12-893-74) from the Instituto Nacional de Previsión, Spain, by a research contract (No.1551/Rb) from the International Atomic Energy Agency, Vienna, Austria, and by a gift from the Alexander von Humboldt Stiftung, Bonn-Bad Godesberg, Federal Republic of Germany
}

In gastrectomized patients, the secretion of intestinal glucagon-like immunoreactivity (GLI) observed throughout the course of an oral glucose tolerance test (OGTT) is more intense (three-fivefold) than in normal subjects $[1,2,3,4,5,6]$. Arising from these findings, speculation has been made about the possible implication of high levels of circulating GLI in the pathogenesis of some aspects of the postgastrectomy syndrome, such as dumping [5] and reactive hypoglycaemia [6]. However, the aforementioned condition, induced by the ingestion of a large amount of glucose solution, is obviously not a physiological situation.

To obtain information about the effect of ingestion of natural foodstuffs on GLI secretion, in the present work we have examined the plasma GLI levels after consumption of carbohydrate and protein-rich meals in normal and gastrectomized subjects.

\section{Materials and Methods}

The control group consisted of six healthy volunteers (four males and two females) whose ages ranged from 24 to 46 years. None of them appeared to be obese ( $\pm 10 \%$ ideal body weight according to the Metropolitan Life Insurance Company tables). The test group consisted of six male subjects who had undergone subtotal gastric resection (Billroth II) because of the presence of a benign ulcer not controllable by medical treatment. Their ages ranged from 32 to 48 years. None of them were underweight by more than $10 \%$ of the ideal body weight and none suffered from other apparent illness.

All individuals were subjected to three tests. First, to an oral glucose tolerance test; glucose (1.75 g per $\mathrm{kg}$ of body weight) was taken as a $25 \%$ 
solution in five minutes. Second, they were given a carbohydrate-rich meal consisting of white bread, marmalade and fruit-juice, with an estimated carbohydrate content close to $1.75 \mathrm{~g}$ per $\mathrm{kg}$ of body weight. And third, they ate a protein-rich meal consisting of $250-400 \mathrm{~g}$ of grilled lean beef. The meals were consumed in time periods varying from 12 to 18 minutes. In the figures, the 15-minute sample corresponds to the end of the meal.

The subjects reported to the laboratory between 9 and 10 a.m. after an overnight fast. To obtain samples, an indwelling butterfly needle connected to a tap was inserted in an antecubital vein. A period of 20 minutes was allowed for relaxation before collection of the first control sample. Blood specimens $(12 \mathrm{ml})$ were drawn at intervals of five, 10,15 or 30 minutes throughout the tests. For glucose, alphaamino nitrogen and insulin measurements, $7 \mathrm{ml}$ of blood was placed in chilled tubes containing EDTA. For glucagon and GLI analysis, $5 \mathrm{ml}$ of blood was collected in chilled tubes containing EDTA and $2500 \mathrm{U}$ of kallikrein-trypsin inhibitor (Trasylol, Bayer) in a volume of $0.5 \mathrm{ml}$. The blood was promptly centrifuged at $4^{\circ} \mathrm{C}$, and the plasma was stored at $-20^{\circ} \mathrm{C}$ until the time of assay, not more than six weeks later.

All samples were tested in duplicate. Plasma glucose was determined by means of a commercial glucose-oxidase preparation (Biochemica Test Combination, Boehringer Mannheim $\mathrm{GmbH}$ ). Alphaamino nitrogen was analyzed colorimetrically [7]. Glucagon and intestinal GLI were assayed radioimmunologically [8]; the antisera employed in these estimations were kindly donated by Dr.Roger H. Unger. Antiserum 78J possesses great affinity for intestinal GLI [9]. As is well known, however, GLI values are read against crystalline glucagon standards and they should be regarded as glucagonequivalents. Antiserum $30 \mathrm{~K}$ is considered to be specific for true glucagon, either pancreatic or extrapancreatic [10]; nevertheless, in conditions characterized by a great elevation of plasma GLI, an increase of $30 \mathrm{~K}$-glucagon immunoreactivity has been observed. According to Sakurai et al. [11], the crossreactivity of antiserum $30 \mathrm{~K}$ with circulating GLI, as measured with antiserum $78 \mathrm{~J}$, would be about 2 per cent and similar results (3-4 per cent) have been obtained in our laboratory [12]. Furthermore, in acid-alcohol extracts of dog ileum the immunoreactivity detected with antiserum $30 \mathrm{~K}$ represents from 1.5 to 2.5 per cent of that measured with antiserum $78 \mathrm{~J}$ (unpublished observations). Insulin levels were determined by the method of Yalow and Berson [13], as modified by Herbert et al. [14].

Differences between values were tested for significance by Student's t-test.

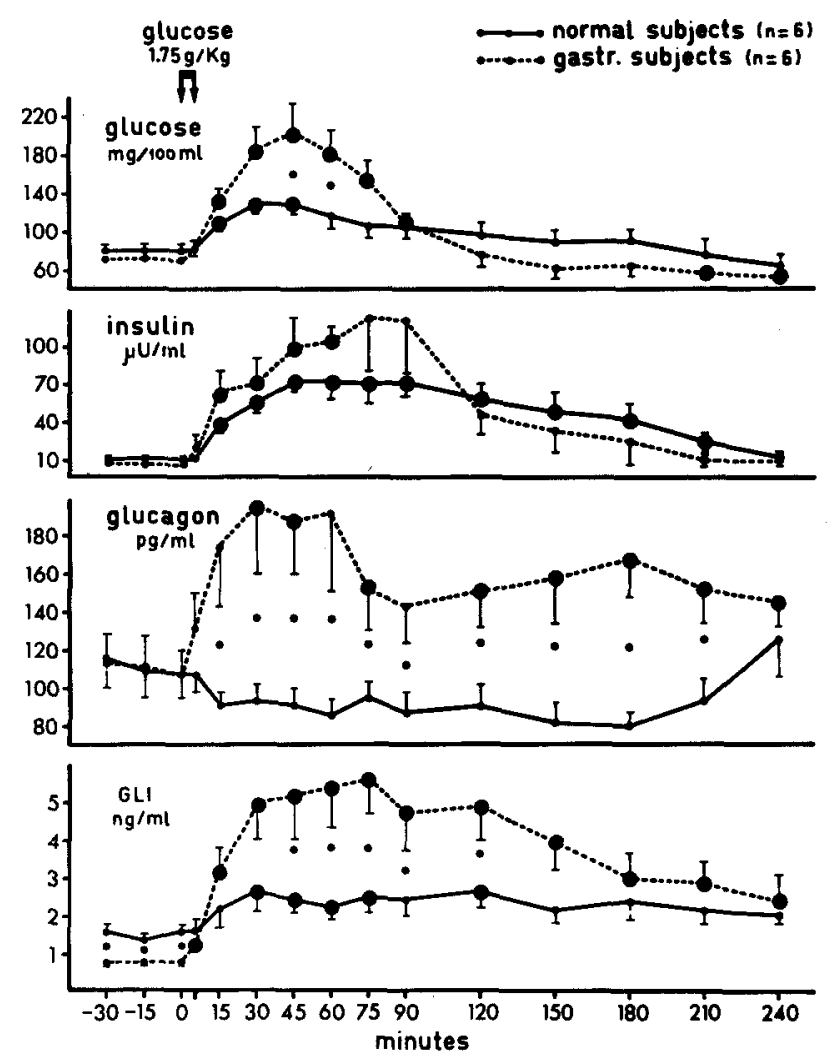

Fig. 1. Effect of the oral administration of a glucose solution $(1.75 \mathrm{~g} / \mathrm{kg}, 25 \%)$ on plasma GLI and glucagon levels in normal and gastrectomized subjects. (Means \pm SEM). The large dots represent statistically significant differences from the baseline values, and the asterisks, statistically significant differences between both groups at a given time

\section{Results}

Effect of the Oral Administration of a Glucose Solution $(1.75 \mathrm{~g} / \mathrm{kg})$ on Plasma GLI and Glucagon Levels in Normal and Gastrectomized Subjects (Fig. 1)

As expected, in the gastrectomy group the oral administration of a large glucose load was followed by a prompt and considerable elevation of circulating GLI (from 0.85 to $5.65 \mathrm{ng} / \mathrm{ml}$ at $75 \mathrm{~min}$; $\mathrm{p}<$ $0.002)$; this rise closely resembled that reported by us in a similar experiment using the same radioimmunoassay system [2]. The normal subjects displayed a modest but statistically significant increase in plasma GLI during the OGTT (from 1.57 to $2.65 \mathrm{ng} / \mathrm{ml}$ at $120 \mathrm{~min} ; \mathrm{p}<0.03$ ), again in agreement with our previous data. Lower basal plasma GLI concentrations were found in the gastrectomized patients as compared to the controls (from 0.56 to $0.75 \mathrm{ng} / \mathrm{ml} ; \mathrm{p}<0.05$ at $-30 \mathrm{~min} ; \mathrm{p}<0.01$ at $-15 \mathrm{~min}$ and at $0 \mathrm{~min}$ ). 


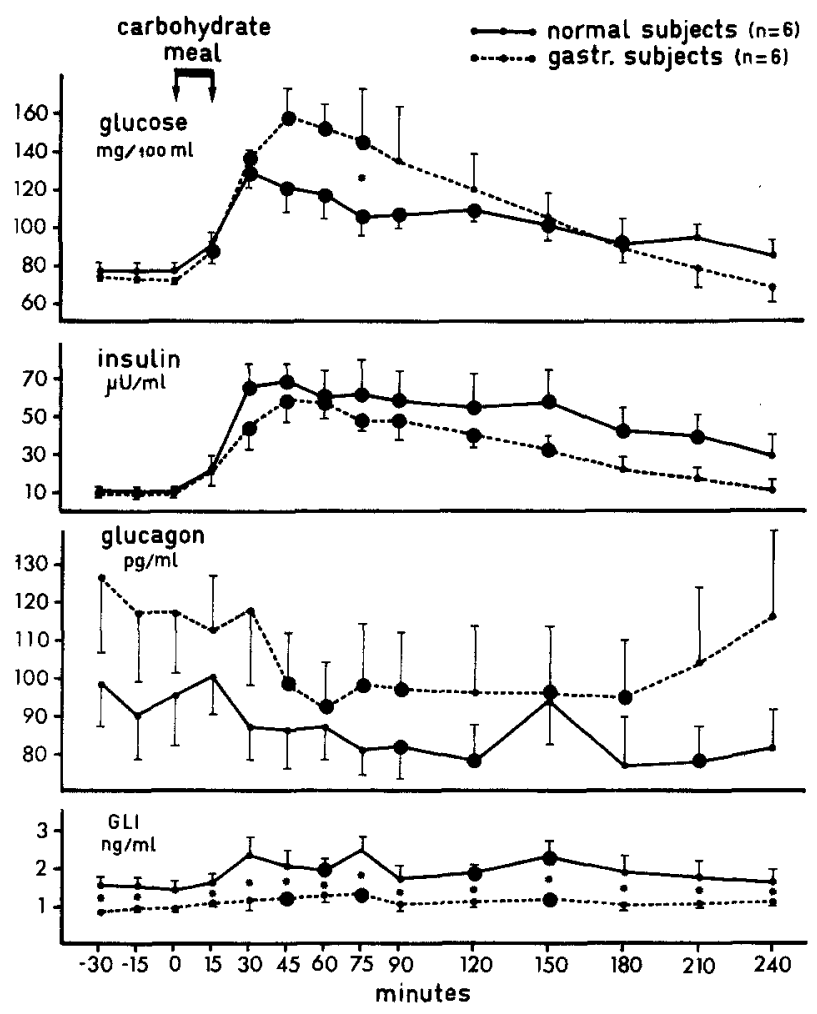

Fig. 2. Effect of the ingestion of a carbohydrate-rich meal (carbohydrate content close to $1.75 \mathrm{~g} / \mathrm{kg}$ ) on plasma GLI and glucagon levels in normal and gastrectomized subjects. (Means \pm SEM). The large dots represent statistically significant differences from the baseline values, and the asterisks, statistically significant differences between both groups at a given time

In the control group after glucose intake, a depression of plasma glucagon levels, which ranged from 16 to $30 \mathrm{pg} / \mathrm{ml}$, was observed, although the differences did not attain the 5 per cent level of statistical significance (p: 0.09 at $30 \mathrm{~min}, 0.06$ at 60 $\mathrm{min}, 0.09$ at $150 \mathrm{~min}$, and 0.06 at $180 \mathrm{~min}$ ). On the other hand, in the gastrectomized subjects glucose ingestion was followed by an elevation of plasma $30 \mathrm{~K}$-glucagon immunoreactivity values.

A greater increment of the glycaemia, along with higher but not statistically significant plasma insulin concentrations, was also detected in the gastrectomized patients when compared to the controls.

\section{Effect of the Ingestion of a Carbohydrate-Rich Meal} on Plasma GLI and Glucagon Levels in Normal and Gastrectomized Subjects (Fig. 2)

In contrast to the preceding experiments, the gastrectomized patients responded to the ingestion of a carbohydrate-rich meal with a slight elevation of

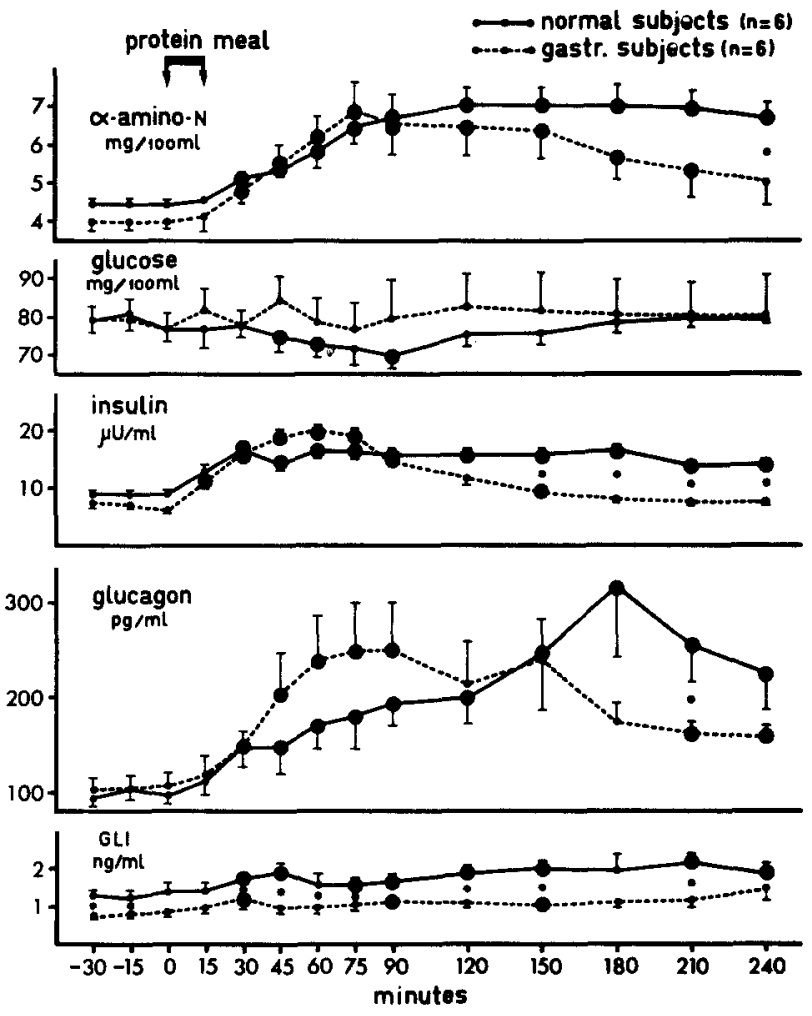

Fig. 3. Effect of the ingestion of a protein-rich meal (250-400 g grilled lean beef) on plasma GLI and glucagon levels in normal and gastrectomized subjects. (Means \pm SEM). The large dots represent statistically significant differences from the baseline values, and the asterisks, statistically significant differences between both groups at a given time

plasma GLI values. The maximal rise $(0.4 \mathrm{ng} / \mathrm{ml})$ was even smaller than that of the controls $(1 \mathrm{ng} / \mathrm{ml})$, whose curve resembled that of the OGTT. A trend toward sub-baseline glucagon concentrations was observed after the meal, the decline being similar in both groups $(17-25 \mathrm{pg} / \mathrm{ml})$. The elevation of the glycaemia was more pronounced in the gastrectomized subjects than in the controls; however, it was not accompanied by greater insulinaemia.

Effect of the Ingestion of a Protein-Rich Meal on Plasma GLI and Glucagon Levels in Normal and Gastrectomized Subjects (Fig. 3)

The ingestion of a protein-rich meal elicited a small increase of plasma GLI in both groups (from 1.33 to $2.22 \mathrm{ng} / \mathrm{ml}$ in the gastrectomized subjects; from 0.88 to $1.28 \mathrm{ng} / \mathrm{ml}$ in the controls), along with a clear rise in circulating glucagon. The elevation of insulin and plasma alpha-amino nitrogen levels was more prolonged in the control group than in the gastrectomized patients. 


\section{Discussion}

The data reported here confirm the exaggerated GLI response to oral glucose in gastrectomized subjects. However, in these patients the ingestion of a similar amount of carbohydrate, in the form of natural foodstuffs, elicited an elevation of circulating GLI analogous to, or even smaller than, that found in the controls. The mean basal GLI level of the gastrectomy group was slightly lower than that of the normal volunteers. This difference could be attributed to the removal of gastrointestinal tissue, thus diminishing the number of GLI-secreting cells.

Although the intimate process of GLI secretion is unknown, it is thought that in gastrectomized subjects the rapid influx of free glucose into the intestine and its subsequent prompt absorption, would be responsible for overstimulation of the GLI-releasing mechanism. This effect would not be brought about by more complex sugars, whose absorption requires previous cleavage and occurs at a slower rate. The fact that in dogs the intraduodenal administration of mannitol, a nonabsorbable monosaccharide, failed to cause an elevation of plasma GLI [15], does not support the concept that osmotic changes at the level of the intestinal lumen play a role in triggering GLI release.

Bloom and associates [5] have reported that the elevation of plasma GLI induced by oral glucose in gastrectomized subjects was more intense in those who had the symptoms of the dumping syndrome than in those without these manifestations. Our data do not exclude the possibility that intestinal GLI could in some way be related to the dumping syndrome, as provoked by large oral glucose loads. However, if such a relationship does exist, it should not be considered when applied to the daily life of these patients, who respond to considerable quantities of carbohydrate and protein, taken as common foodstuffs, with only normal elevations of circulating GLI.

Elevated levels of plasma GLI have also been invoked by Rehfeld et al. [6] as a possible causative factor in the reactive hypoglycaemia of the gastrectomized patient. These authors suggested that a massive arrival of GLI from the intestine to the liver would partially occupy the glucagon receptors of the hepatocyte, which, according to Bataille et al. [16], would also bind GLI peptides, therefore hindering the glucose-mobilizing effect of true glucagon on this organ. In fact, the decline of glycaemia observed toward the end of the OGTT was more marked in our gastrectomized patients than in the controls. However, our results would rule out the possibility that such competition between GLI and glucagon may be operative under the normal dietary conditions of gastrectomized patients.

With regard to glucagon secretion, in the gastrectomy group after the protein meal, an earlier decline of plasma glucagon levels was observed; this might be reasonably related to the less sustained elevation of blood alpha-amino nitrogen. It should be mentioned that in humans there is no evidence indicating the existence of true glucagon of gastric origin $[17,18]$. The increase of circulating "glucagon" found during the OGTT in these patients should be interpreted as crossreactivity of antiserum $30 \mathrm{~K}$ with the high amount of GLI in plasma. In the present experiments the degree of crossreactivity found for this antiserum with circulating GLI (2.5-3.6 per cent of $78 \mathrm{~J}$ values) is very similar to that observed by Sakurai et al. in dogs [11], and by us in another series of gastrectomized subjects [12].

Finally, the results obtained with the ordinary nutritional stimuli we have employed provide no support for alimentary hyperinsulinism as a characteristic feature of the gastrectomized patient.

Acknowledgements. The expert technical assistance of Ms. Ana Ramírez, Ms. Begoña Samper and Ms. Inés García is gratefully appreciated.

\section{References}

1. Samols, E., Marks, V.: Nouvelles conseptions sur la signification du glucagon (pancréatique et extrapancréatique). Journ. Annu. Diabetol. Hotel-Dieu 43-66 (1967)

2. Marco, J., Baroja, I. M., Dỉaz-Fierros, M., Villanueva, M.L., Valverde, I.: Relationship between insulin and gut glucagonlike immunoreactivity (GLI) secretion in normal and gastrectomized subjects. J. Clin. Endocrinol. 34, 188-191 (1972)

3. Vance, J.E., Stoll, R.W., Fariss, B.L., Williams, R.H.: Exaggerated intestinal glucagon and insulin responses in human subjects. Metabolism 21, 405-412 (1972)

4. Shima, K., Kuroda, K., Matsuyama, T., Tarui, S., Nishikawa, M.: Plasma glucagon and insulin responses to various sugars in gastrectomized and normal subjects. Proc. Soc. Exp. Biol. (N. Y.) 139, 1042-1048 (1972)

5. Bloom, S.R., Royston, C.M. S., Thompson, J.P. S.: Enteroglucagon release in the dumping syndrome. Lancet 1972 II, 789-791

6. Rehfeld, J. F., Heding, L. G., Holst, J. J.: Increased gut glucagon release as pathogenic factor in reactive hypoglycemia? Lancet 1973 I, 116-118

7. Frame, E. G., Russell, J.A., Wilhelmi, A. E.: The colorimetric estimation of amino nitrogen in blood. J. Biol. Chem. 149, 255-270 (1943)

8. Faloona, G.R., Unger, R.H.: Glucagon. In: B.M. Jaffe, H.R. Behrman (Eds.): Methods of hormone radioimmunoassay, pp. 317-320. New York: Academic Press, Inc. 1974

9. Eisentraut, A. M., Ohneda, A., Parada, E., Unger, R. H.: Immunologic discrimination between pancreatic glucagon and 
enteric glucagon-like immunoreactivity (GLI) in tissues and plasma (Abstract). Diabetes 17 (Suppl. 1), 321-322 (1968)

10. Sasaki, H., Rubalcava, B., Baetens, D., Blazquez, E., Srikant, C. B., Orci, L., Unger, R. H.: Identification of glucagon in the gastrointestinal tract. J. Clin. Invest. 56, 135-145 (1975)

11. Sakurai, H., Dobbs, R.E., Unger, R.H.: The effect of somatostatin on the response of GLI to the intraduodenal administration of glucose, protein, and fat. Diabetologia 11, $427-430$ (1975)

12. Marco, J., Hedo, J. A., Villanueva, M.L.: Inhibition of intestinal glucagon-like immunoreactivity (GLI) secretion by somatostatin in man. J. Clin. Endocr. (in press)

13. Yalow, R.S., Berson, S. A.: Immunoassay of endogenous plasma insulin in man. J. Clin. Invest. 39, 1157-1175 (1970)

14. Herbert, V., Lau, K.-S., Gottlieb, C.W., Bleicher, S. J.: Coated charcoal immunoassay of insulin. J. Clin. Endocrinol. 25, 1375-1384 (1965)

15. Marco, J., Faloona, G. R., Unger, R. H.: Effect of endogenous intestinal glucagon-like immunoreactivity (GLI) on insulin secretion and glucose concentrations in dogs. J. Clin. Endocrinol. 33, 318-325 (1971)
16. Bataille, D.P., Freychet, F., Kitabgi, P.E., Rosselin, G.E.: Gut glucagon: a common receptor site with pancreatic glucagon in liver cell plasma membranes. FEBS Lett. 30, 215-218 (1973)

17. Marco, J., Hedo, J.A., Villanueva, M. L.: Presence of big plasma glucagon in a totally pancreatectomized patient (Abstract). Diabetes 24 (Suppl. 2), 411 (1975)

18. Barnes, A.J., Bloom, S. R.: Pancreatectomized man: a model for diabetes without glucagon. Lancet 1976 I, 219-221

Received: August 23, 1976, and in revised form:

December 22, 1976

Dr. J. Marco

Clinica Puerta de Hierro

Universidad Antónoma de Madrid

San Martin du Porres 4

Madrid 35

Spain 